Article

\title{
Properties of Pectin Extracted from Vietnamese Mango Peels
}

\author{
Hoa H. D. Nguyen ${ }^{1}$, Ha V. H. Nguyen ${ }^{1, *}$ and Geoffrey P. Savage ${ }^{2}$ \\ 1 Food Technology Department, Biotechnology School, International University, Vietnam National University, \\ Ho Chi Minh City 700000, Vietnam; hoanghoa19sep@gmail.com \\ 2 Food Group, Department of Wine, Food and Molecular Biosciences, Agriculture and Life Sciences, \\ Lincoln University, Canterbury 7674, New Zealand; Geoffrey.Savage@lincoln.ac.nz \\ * Correspondence: nvhha@hcmiu.edu.vn; Tel.: +84-8-3724-4270
}

Received: 29 October 2019; Accepted: 28 November 2019; Published: 1 December 2019

check for updates

\begin{abstract}
This study was carried out to investigate the properties of pectin extracted from Vietnamese mango peels that have been discarded as waste. Three different mango cultivars named Hoa Loc, Ghep and Cat Chu at three different maturities were studied. Pectin extracted from immature, ripe and overripe stages ranged from 18.4 to $31.7 \mathrm{~g} / 100 \mathrm{~g}$ dry weight (DW); the highest yields were obtained from the ripe fruits. Ghep peels contained the highest pectin amounts which ranged from 24.2 to $31.7 \mathrm{~g} / 100 \mathrm{~g}$ DW, followed by Cat Chu (19.2 to $26.5 \mathrm{~g} / 100 \mathrm{~g} \mathrm{DW}$ ) and Hoa Loc peels (18.4 to $24.1 \mathrm{~g} / 100 \mathrm{~g}$ DW). Except for degree of esterification and emulsion capacity, other properties of the extracted pectin including water holding capacity, solubility and emulsion stability were significantly affected by the fruit maturation. Varieties, solubility, degree of esterification, emulsion activity and emulsion stability of the pectin isolated from the three cultivars ranged from $77.4 \%$ to $86.0 \% ; 50.3 \%$ to $55.8 \% ; 11.8 \%$ to $34.3 \%$ and $28.5 \%$ to $94.5 \%$, respectively. Fourier-transform infrared results showed that almost all collected pectin samples could be classified as the high methoxyl pectin. Rheology data indicated viscosity of the isolated pectin was strongly dependent on temperatures.
\end{abstract}

Keywords: mango peel pectin; mango cultivars; maturity stages; Fourier-transform infrared spectroscopy (FTIR); rheological property

\section{Introduction}

Pectins are complex colloidal acid polysaccharides [1]. Pectic substances have high molecular weights and can be classified into four groups: protopectin, pectic acid, pectinic acid and pectins [2]. Pectins are widely used as thickening and stabilizing agents in beverages, dairy products and confections due to their gelation properties [1,2]. They are also applied in pharmaceutical products to reduce the absorption of cholesterol [3], control haemorrhage and effect of poisoning of toxic cations [1]. In the upper intestine, pectin can reduce postprandial satiety, the absorption of nutrients and the motility of the intestinal tract [4].

High levels of pectins are found in almost all fruit fractions including peels, pulp and kernels [5-7]; however, the pectin yield depends very much on the cultivars and the maturity stages when a fruit is harvested and analysed [8,9].

The major constituent of pectin molecules is poly (1-4)- $\alpha$-D-galacturonan, which contains carboxyl groups presenting in either free acid or methyl ester forms. The result of dividing esterified carboxylic acid units into total carboxylic acid groups in the pectin chain has been defined as the degree of esterification (DE). The DE value of pectin is an important functional property that significantly influences its commercial use as a gelling or thickening agent. The degree of esterification is strongly influenced by calcium cations, sugar and acid concentrations. Depending on the proportion of the 
esterified groups, pectin is classified into low methoxyl pectin (LMP) (DE $<50 \%$ ) and high methoxyl pectin (HMP) (DE $>50 \%$ ) [1]. Structural differences between pectin molecules affect the gelling mechanisms of LMP and HMP; hence, their applications in foodstuffs are also different.

Although pectin has been commonly extracted from agricultural byproducts, the number of sources used for extracting commercial pectin production is limited [10]. The gel forming ability of pectin strongly depends on the molecular size and degree of esterification of each different byproduct; therefore, the isolation and characterization of pectin from each new source are important for the development of a new pectin product.

In Vietnam, mangoes (Mangifera indica L.) are grown in most southern regions (approximately 75,000 hectares in total) producing 0.5 million tons of mangoes/year of which $70 \%$ is used for processing [11]. Mango processing releases large amounts of byproducts consisting of $35-60 \%$ of total fruit weight. This fraction includes peels, stones and sometimes parts of perishable pulp [12]. Dorta et al. [13] reported that the world mango production produces approximately 75,000 tons of mango wastes/year. As mango peels constitute $15-20 \%$ of the fruit weight, the production of mango waste in Vietnam would be between 50,000 and 70,000 tons/year. Currently, these wastes have been used for animal feeding or dumped as rubbish; therefore, there is an urgent need to use this waste resource effectively. Many experiments have been carried out using mango byproducts in order to reduce the negative effects of disposing this waste product. Interestingly, it has been found that mango peels are a good source of dietary fiber including pectin, polyphenols, carotenoids and other bioactive compounds that have positive influences on human health $[13,14]$. Extractions of pectin from mango peels have been carried out by Al-Sheraji et al. [5] and Ajila and Prasada Rao [14]; however, effects of biological factors including maturity stages and cultivars on properties of pectin have been overlooked. Moreover, it is noticeable that Vietnamese processors have to pay more than United States Dollar 4 million annually to import pectin from other countries [15]. Therefore, analysing physiochemical properties of pectin extracted from a few common cultivars of mango is an important step to improve the utilisation of this useful byproduct.

\section{Materials and Methods}

\subsection{Sample Preparation}

In brief, $180 \mathrm{~kg}$ of three different cultivars of healthy mangoes; Hoa Loc, Cat Chu and Ghep were harvested from a farm in Tien Giang province, Vietnam in November 2015. The three cultivars harvested at three different maturity stages: pre-mature, mature and ripe were transported to the laboratory of the International University, Thu Duc District, Ho Chi Minh City and processed further on the same day. The fruits were carefully washed under running tap water to remove any dirt, insects and debris on surface of the fruits. Peels then were separated from fruits using a stainless-steel knife and dried in an oven (WiseVen, Wisd Laboratory Instruments, Gangwon-do, Korea) at $60^{\circ} \mathrm{C}$ for $24 \mathrm{~h}$. The dried samples were ground into a fine powder using an A11 grinder (IKA, Selangor, Malaysia) and then packed in individual plastic bags and stored in desiccators until analysis commenced.

\subsection{Pectin Extraction from Dried Mango Peel Powder}

Pectin extractions were carried out following the procedure of Nguyen and Savage [6] with some modifications. The dried peel powder of each cultivar at different maturity stages was mixed with the aqueous solution of citric acid (Merck Sharp \& Dohme Corp., Kenilworth, NJ, USA) $1.5 \%$ in a ratio 1:40 (w/v). The mixture was stirred continuously for $20 \mathrm{~min}$ and then filtered through four layers of cheesecloth in order to separate the supernatant from the insoluble fraction. Pectin was precipitated by the addition of absolute ethanol (98\% purity) with a ratio of $1: 2(w / w)$ into the supernatant and kept overnight at room temperature. The precipitated pectin was then washed three times with $75 \%, 85 \%$ and $98 \%(v / v)$ ethanol to remove the soluble impurities. The pellet was then freeze-dried 
(FreeZone 2.5 L Benchtop Freeze Dry System, Labconco, Kansas city, MO, USA) until a constant weight was obtained.

\subsection{Pectin Yield}

$$
\text { The yield }(\%)=\frac{\text { weight of dried pectin }(\mathrm{g}) \times 100}{\text { weight of dried peel taken for extraction }(\mathrm{g})}
$$

\subsection{Measurement of the Degree of Esterification}

The collected pectin was stored in vacuumed bags at $4{ }^{\circ} \mathrm{C}$ before measuring their degree of esterification by Fourier-transform infrared spectroscopy (FTIR) analysis. In detail, FTIR spectra of pectin samples were obtained using a Tensor 27 Spectrophotometer (Bruker AXS GmbH., Karlsruhe, Germany) that measured the absorbance of asymmetrical stretching vibrations of the carboxyl groups (1600-1630 $\mathrm{cm}^{-1}$ wavenumber) and carbonyl groups originating from carboxyl and carbomethoxyl groups (1730-1760 $\mathrm{cm}^{-1}$ wavenumber) on $\mathrm{KBr}$ disks with a 90:10 KBr/pectin ratio. Then, the degree of esterification was calculated using the equation proposed by Singthong et al. [16].

\subsection{Determination of Water Holding Capacity (WHC) and Solubility of Mango Peel Pectin}

These properties were determined using centrifugation techniques by modifying the method of Eastwood et al. [17]. In detail, $0.3-0.5 \mathrm{~g}$ of pectin samples were soaked in $20 \mathrm{~mL}$ of Nanopure water and left to stand for 1 hour at room temperature before centrifugation at $6000 \mathrm{rpm}$ for $15 \mathrm{~min}$. Then, the supernatant fraction was discarded and the pellets were left to drain during $30 \mathrm{~min}$ at ambient temperature. The pellets were dried until obtaining the constant weight.

The changes in weight of pellet were recorded and the WHC and solubility of pectin samples were conducted

$$
\begin{gathered}
\text { Water holding capacity }=\frac{\mathrm{m}_{\mathrm{w}}-\mathrm{m}_{\mathrm{d}}}{\mathrm{m}_{\mathrm{d}}}\left(\mathrm{g} \mathrm{H}_{2} \mathrm{O} / \mathrm{g} \text { dried pectin }\right) \\
\text { Solubility }=\mathrm{m}_{\mathrm{i}}-\mathrm{m}_{\mathrm{d}}(\%),
\end{gathered}
$$

where: $\mathrm{m}_{\mathrm{i}}$ : initial weight of dried pectin samples before WHC processing; $\mathrm{m}_{\mathrm{w}}$ : wet weight of pectin samples; $\mathrm{m}_{\mathrm{d}}$ : dried weight of pectin samples after WHC processing.

\subsection{Determination of the Emulsion Activity and Emulsion Stability}

To measure the emulsion activity of the collected pectin, two volumes of prepared pectin gel $(60 \mathrm{~mL})(0.5 \% w / v$ pectin solution) were thoroughly mixed with the soybean oil $(6 \mathrm{~mL})$ [18]. The mixture was then homogenized (HG-15A, Witeg Labortechnik GmbH, Wertheim, Germany) for 1 min and then centrifuged (Z326K, Hermle Labortechnik GmbH., Wehingen, Germany) at $800 \mathrm{~g}$ for $10 \mathrm{~min}$. The emulsion activity was calculated as the ratio of the volume of emulsified layer with the volume of whole layer in centrifuge tube. For the determination of the emulsion stability, emulsions prepared by the above procedures were heated at $80^{\circ} \mathrm{C}$ for $30 \mathrm{~min}$ and cooled to room temperature [18]. Then, the content was centrifuged at $800 \mathrm{~g}$ for $10 \mathrm{~min}$. The emulsion stability was measured as the ratio between the remaining emulsified layer in the supernatant and the initial emulsified layer.

\subsection{Rheological Analysis}

Rheological analysis of the pectin solutions was performed in a HAAKE viscometer and rheometer RheoStress 6000 (Thermo Scientific, Waltham, MA, USA). Thermo Scientific HAAKE RheoWin software (Thermo Scientific, USA) was run to record shear stress $(\tau)$ and shear rate $(\gamma)$ values. Pectin $\left(10 \mathrm{~g} \mathrm{~L}^{-1}\right)$ were dissolved in $0.1 \mathrm{~mol} \mathrm{~L}^{-1}$ sodium chlorine solutions (Merck Sharp \& Dohme Corp., Kenilworth, $\mathrm{NJ}, \mathrm{USA}$ ) and left for $12 \mathrm{~h}$ at room temperature prior to measuring [19]. The flow curves were obtained 
at different processing temperatures $4{ }^{\circ} \mathrm{C}, 30{ }^{\circ} \mathrm{C}$ and $50{ }^{\circ} \mathrm{C}$. The shear rates from 10.0 to $300 \mathrm{~s}^{-1}$ were chosen.

\subsection{Determination of Viscosity-average Molecular Mass}

Dried pectin $0.25 ; 0.5 ; 1.0 ; 1.5$ and $2.0 \mathrm{~g}$ was dissolved in $100 \mathrm{~mL}$ of $0.1 \mathrm{M}$ potassium phosphate $(\mathrm{pH}$ : 7.0) [20]. The viscosity measurement was performed at $25^{\circ} \mathrm{C}$ using a Cannon-Fenske viscometer tube, size 100 (sigma-aldrich, Germany) with constant $\mathrm{k}=0.015$. Specific, reduced and intrinsic viscosities were calculated by the following equations:

$$
\begin{aligned}
& \text { Specific viscosity : } \eta_{s p}=\frac{t-t_{0}}{t} \\
& \text { Reduced viscosity }: \eta_{r e d}=\frac{\eta_{s p}}{C} \\
& \text { Intrinsic viscosity }: \eta_{i}=\lim _{C \rightarrow 0} \frac{\eta_{s p}}{C},
\end{aligned}
$$

where: $t$ is time taken by the solution to flow in viscometer $(\mathrm{s}) ; t_{0}$ is time taken by the solvent to flow in viscometer; $C$ the concentration of pectin solution $(\mathrm{g} / 100 \mathrm{~mL})$

The relationship between intrinsic viscosity and molecular mass is described by the Mark-Houwink-Sakurada equation [21]:

$$
\eta_{i}=\mathrm{K} \times \mathrm{M}_{\mathrm{w}}^{\alpha}
$$

where: $\mathrm{K}$ and $\alpha$ are constants. At $25^{\circ} \mathrm{C}, \mathrm{K}$ and $\alpha$ are $1.4 \times 10^{-6}$ and 1.34 , respectively [22].

\subsection{Statistical Analysis}

The results were presented as mean of three determinations \pm standard error. Two-way analysis of variance (ANOVA) was performed using Minitab software version 16.0 for Windows 7 (Minitab Pty Ltd., Sydney, NSW, Australia) with a level of confidence of 95\%.

\section{Results and Discussion}

\subsection{Pectin Yield}

The yield of pectin extracted from the peels of each of the three mango cultivars at ripening stage was significantly higher $(p<0.05)$ when compared to the mature stage (Table 1$)$. The amounts of pectin extracted from the mature stage of the Cat Chu and Hoa Loc cultivars gave intermediate values and significantly lower levels for Ghep. Similar observations were made by Proctor and Peng [23] who noted that amounts of extracted pectin declined steadily before the fruits reached full maturation but increased during fruit ripening. During fruit ripening, polygalacturonase and pectin methyl esterase hydrolyse the pectin backbone and solubilize insoluble protopectin into soluble pectin; consequently, more soluble pectin is produced [24]. However, the activity of pectin methyl esterase was highest in over-ripe and in immature fruit. Meanwhile, the polygalacturonase activity was very low in unripe fruit [24]. Moreover, pectinolytic enzyme activities, especially polygalacturonase, have been reported to be different between fruit cultivars [9]. Therefore, the differences in amounts of pectin observed at different maturity stages and cultivars may be due to the different activities of both pectin methyl esterase and polyglacturonase, which are active during the development of the fruit $[8,9,24]$. 
Table 1. Properties of crude pectin extracted from peels of three Vietnamese mango cultivars at three maturity stages.

\begin{tabular}{|c|c|c|c|c|c|c|c|c|}
\hline $\begin{array}{l}\text { Cultivars } \\
\text { Samples }\end{array}$ & $\begin{array}{l}\text { Pectin Yield } \\
\text { (g/100 g DW) }\end{array}$ & $\begin{array}{c}\text { Degree of } \\
\text { Esterification } \\
(\%)\end{array}$ & $\begin{array}{c}\text { Water Holding } \\
\text { Capacity } \\
\text { (g H } \mathrm{H}_{2} \mathrm{O} / \mathbf{1} \text { g pectin) }\end{array}$ & Solubility (\%) & $\begin{array}{c}\text { Emulsion } \\
\text { Activity (\%) }\end{array}$ & $\begin{array}{c}\text { Emulsion } \\
\text { Stability (\%) }\end{array}$ & $\begin{array}{c}\text { Intrinsic } \\
\text { Viscosity } \\
(\mathrm{mL} / \mathrm{g})\end{array}$ & $\mathrm{M}_{\mathrm{w}}(\mathrm{kDa})$ \\
\hline \multicolumn{9}{|c|}{ Ghep } \\
\hline Pre mature & $27.5 \pm 1.2$ & $55.8 \pm 0.7$ & $11.4 \pm 0.2$ & $81.7 \pm 1.3$ & $34.2 \pm 0.3$ & $65.8 \pm 9.3$ & $46.3 \pm 0.1$ & $397.0 \pm 1.4$ \\
\hline Mature & $24.2 \pm 0.7$ & $55.8 \pm 0.2$ & $11.6 \pm 0.8$ & $87.4 \pm 1.6$ & $31.8 \pm 1.7$ & $40.2 \pm 3.8$ & $50.3 \pm 0.2$ & $444.5 \pm 0.8$ \\
\hline Ripe & $31.7 \pm 1.0$ & $55.7 \pm 0.5$ & $13.6 \pm 0.4$ & $86.0 \pm 1.4$ & $29.9 \pm 0.4$ & $39.5 \pm 3.4$ & $50.1 \pm 0.2$ & $434.6 \pm 1.2$ \\
\hline \multicolumn{9}{|c|}{ Cat Chu } \\
\hline Pre mature & $21.0 \pm 0.7$ & $50.9 \pm 0.5$ & $10.6 \pm 0.3$ & $77.4 \pm 0.5$ & $19.4 \pm 4.0$ & $35.5 \pm 6.0$ & $67.2 \pm 0.3$ & $539.8 \pm 1.0$ \\
\hline Mature & $19.2 \pm 0.4$ & $49.6 \pm 0.2$ & $14.9 \pm 1.1$ & $79.1 \pm 1.3$ & $11.8 \pm 0.9$ & $60.6 \pm 2.7$ & $73.7 \pm 0.4$ & $578.0 \pm 0.7$ \\
\hline Ripe & $26.5 \pm 0.3$ & $50.3 \pm 0.5$ & $9.5 \pm 0.0$ & $82.5 \pm 1.2$ & $24.2 \pm 2.0$ & $35.6 \pm 0.6$ & $71.3 \pm 0.5$ & $564.0 \pm 1.5$ \\
\hline \multicolumn{9}{|c|}{ Hoa Loc } \\
\hline Pre mature & $20.5 \pm 0.9$ & $52.1 \pm 0.2$ & $11.3 \pm 0.3$ & $83.4 \pm 1.8$ & $30.9 \pm 1.1$ & $85.5 \pm 3.1$ & $44.5 \pm 0.2$ & $408.2 \pm 0.8$ \\
\hline Mature & $18.4 \pm 0.8$ & $52.4 \pm 0.5$ & $13.4 \pm 0.6$ & $85.1 \pm 1.2$ & $33.8 \pm 0.5$ & $94.5 \pm 3.7$ & $52.0 \pm 0.3$ & $444.6 \pm 1.5$ \\
\hline Ripe & $24.1 \pm 1.2$ & $51.0 \pm 0.3$ & $11.8 \pm 0.7$ & $84.6 \pm 1.3$ & $27.6 \pm 3.4$ & $28.5 \pm 5.0$ & $50.3 \pm 0.2$ & $432.8 \pm 1.1$ \\
\hline $\begin{array}{l}\text { Analysis of } \\
\text { variance }\end{array}$ & \multicolumn{8}{|c|}{ Significance } \\
\hline Cultivars & ** & $* *$ & ns & ** & ** & * & * & * \\
\hline Maturity stages & $* *$ & ns & * & $* *$ & ns & $* *$ & ns & ns \\
\hline Interaction & $* *$ & ns & $* *$ & ns & $* *$ & $* *$ & $*$ & $*$ \\
\hline LSD cultivars & 3.1 & 0.8 & - & 2.8 & 4.6 & 21.2 & 1.7 & 9.9 \\
\hline LSD maturity & 4.5 & - & 1.6 & 3.3 & - & 19.6 & - & - \\
\hline
\end{tabular}

Significance: ${ }^{*} p<0.05 ;{ }^{* *} p<0.01$; Data are expressed as means \pm standard error $(n=3)$. ns: not significant; LSD: Least Significant Difference. “-“: not calculated. 
The yield of pectin recovered in this study was much higher than recovered from other mango cultivars, including Améliorée (10.1 g/100 g DW), Mango (15.3 g/100 g DW) [2] and Tommy Atkins (17.6 g/100 g DW) [25].

\subsection{Water Holding Capacity (WHC)}

Water holding capacity, defined as the amount of water held by the fibrous matrix [17], has been shown to be a key physical property of pectin [2]. During ripening, the reduction of insoluble materials of pectic substances is inversely proportional to the increase of water-soluble substances. As a result, the water holding capacity of a fruit would be changed.

The overall mean of water holding capacity of the pectin extracted from the three cultivars of mango was $12.0 \pm 0.17 \mathrm{~g} \mathrm{H}_{2} \mathrm{O} / \mathrm{g}$ DW. The water holding capacity measured at different maturity stages was variable for each of the cultivars but only Ghep showed an increased level when the fruit was fully ripe. It was reported that the side chains of the pectin molecule consist of glucose, arabinose, xylose, galactose, mannose and rhamnose, creating "sugar building blocks" [16]. Furthermore, mangoes are climacteric fruits which have high respiration rates when they are fully mature. At this stage total sugar contents rapidly increase following starch degradation [10]. The high sugar levels coincide with increasing organic acid contents in the mature fruit, causing pectin molecules to no longer repel each other [4]; as a result, they form stable three dimensional networks, allowing more water and sugar molecules to be trapped in the structure of pectin samples extracted [26]. The pectin extracted from this stage is of considerable interest to food processors as it has considerably increased water holding capacity.

However, in the cell wall, organic acids decrease during fruit ripening [10]. This leads to a shortage of protons for balancing the anion carboxylate groups in the pectin structure. Therefore, the approach and interaction among polysaccharide molecules could be suppressed, resulting in an unbalanced network formation which contains weaker bonds [10]. These weak bonding networks may lower the water holding capacity of pectin molecules extracted from fully ripe fruits of Cat Chu and Hoa Loc.

The most interesting feature of the present study is that the WHC in the Vietnamese mango peels was much higher when compared to lemon peels (1.7-1.9 $\mathrm{g} \mathrm{H}_{2} \mathrm{O} / \mathrm{g} \mathrm{DW}$ ) [27], yellow passion fruit peels (3.7-4.1 $\mathrm{g} \mathrm{H}_{2} \mathrm{O} / \mathrm{g}$ DW) [28] and Tommy Atkins mango peels (4.7-6.1 $\mathrm{g} \mathrm{H}_{2} \mathrm{O} / \mathrm{g} \mathrm{DW}$ ) [7]. Significant differences in the WHC of pectin extracted from 12 different cultivars of pomegranates [29] and cabbage [3] have also been observed. The WHC of pectin has an important effect of reducing free water in a gel matrix [30] and the pectin samples extracted in this present study show an important potential function as a food ingredient to prevent syneresis of formulated products [30].

\subsection{Solubility}

The solubility of the pectin extracted from the three different cultivars in this study were significantly different $(p<0.05)$ : overall the levels increased as the fruits matured. The increase in solubility of the pectin extracted as the fruit matures results from the increase in the pectinolytic enzyme activities, especially polygalacturonase and these have been reported to be different between fruit cultivars [9]. The main effect appears to be variations in the reductions of the pectin chain width and removal of the neutral sugars from the side chains [31]. The increase in solubility of the pectin extracted from the three different mango cultivars as they mature is a very important finding of this study.

At the onset of fruit ripening, the hydrolytic enzymes-polygalacturonase and pectin methyl esterase-break down the pectin chain, producing smaller units [24]. In the early stage of fruit ripening, $\beta$-galactosidase enzyme was reported to be responsible for an increasing number of free pectin molecules present in the cell wall [31]. Additionally, $\beta$-galactosidase cuts the sugar chains in the pectin structures into shorter pieces, resulting in an increase in the water solubility of the pectin [31]. As ripening proceeds in fruits, the pectin becomes more soluble; this may not be a positive feature in the use of extracted pectin for food processing applications. 


\subsection{Degree of Esterification}

Many studies have been carried out to measure the degree of esterification (DE) of pectin extracted from different plant sources [32-34], however, investigation of the possible changes in DE in pectin samples extracted from different maturities and cultivars of mangoes using the FTIR method have not been studied.

It was found from the current work that the overall mean DE of the three mango cultivars was $52.6 \pm 1.6 \%$; there were significant differences between the cultivars; however, insignificant changes occurred as the cultivars matured (Table 1). These results could be due to differences in the activities of pectin methyl esterase and $\beta$-galactosidase. The same phenomenon was also observed between 16 different cultivars of tomatoes [35] and two apple cultivars [36].

The overall DE values of the three cultivars investigated in this study were higher than those of pectin, extracted using the same acid hydrolysis extraction method, from apple pomace (22.2\%) [32], dragon fruit peels (31.1-47.0\%) [33] and cocoa pod husk (40.3\%) [34]. The pectin extracted in this study could be considered to be high-methoxyl pectin, which is more desirable and useful in commercial food production where pectin with mean DE values $>50 \%$ is of considerable use in the manufacture of low $\mathrm{pH}$ products like fruit jellies or low-methoxyl pectin through de-esterification process [1].

\subsection{FTIR Analysis}

FTIR spectra analysis, shown in Figure 1, is not only used to determine degree of esterification but also to identify functional groups of the mango peel pectin collected. The functional groups of the pectin were identified based on their corresponding frequencies and the intensities of absorption [37]. Analysis of spectra showed that structural properties of the mango peel pectin samples were not significantly affected by the differences in cultivars and maturity stages (Figure 1). All FTIR spectra were similar and showing the broad and strong absorption areas between 3500 and $2500 \mathrm{~cm}^{-1}$, indicating for $\mathrm{O}-\mathrm{H}$ stretching vibrations due to free and bound hydroxyl groups of carboxylic acid [37]. From $3000 \mathrm{~cm}^{-1}$ to $2800 \mathrm{~cm}^{-1}$, there were sharp bands representing $\mathrm{C}-\mathrm{H}$ absorptions including $\mathrm{CH}$, $\mathrm{CH}_{2}, \mathrm{CH}_{3}$ stretching. The presence of the ester carbonyl $(\mathrm{C}=\mathrm{O})$ groups and carboxylate stretching bands (COO-) were evidenced by stronger bands between 1760 and $1740 \mathrm{~cm}^{-1}$ and between 1640 and $1620 \mathrm{~cm}^{-1}$, respectively. It is obviously seen that for the stronger stretching peaks between 1760 and $1740 \mathrm{~cm}^{-1}$, higher DE values are obtained (Figure 1, Table 1).

\subsection{Emulsifying Properties}

Emulsifying properties include both emulsifying activity (EA) and emulsifying stability (ES). The emulsion activity of the pectin extracted from the three cultivars ranged from $11.8 \%$ to $34.2 \%$. The emulsion activity did not increase as the cultivars matured but there were overall differences between the three cultivars (mean 32.0\% for Ghep, 18.5\% for Cat Chu and 30.8\% for Hoa Loc). Lopez-Franco et al. [38] found that the presence of protein and polysaccharide moities in the pectin led to interactions between electrostatic and steric repulsion forces, forming an interfacial membrane around the oil droplets and this prevents their flocculation and coalesence. They are bound to the neutral sugar side chains of pectin and these act as the anchors that enable the pectin to form an emulsified system [39]. In this system, proteins are active on the oil-water interface and are responsible for the emulsifying activity of pectin [39]. As proteins are found in mango peels [40], the differences in emulsion properties of pectin between the mango cultivars might be due to differences in the protein content of the peels and the neutral sugar side chain in the pectin structure. 


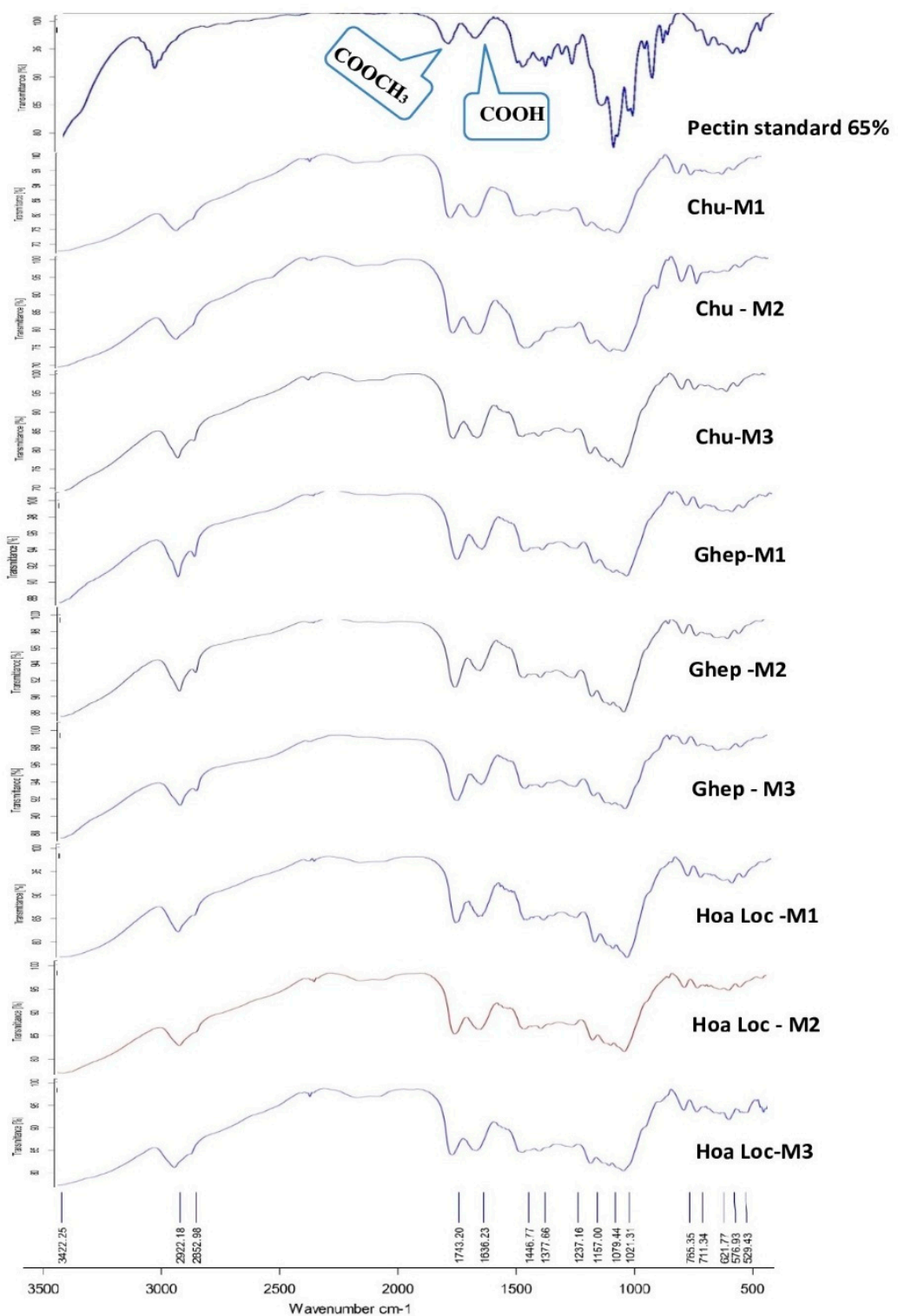

Figure 1. Fourier-transform infrared spectroscopy (FTIR) spectra of mango peel pectin collected from the three mango varieties at different maturity stages. Chu-M1: the immature Chu mango; Chu-M2: the mature Chu mango; Chu-M2: the overripe Chu mango; Ghep-M1: the immature Ghep mango; Ghep-M2: the mature Ghep mango; Ghep-M2: the overripe Ghep mango.

In the current work, the emulsion stability of the pectin extracted from the peels was very variable. It is interesting to note that overall the emulsion stability of the pectin extracted from the mature peels (mean $65.1 \%$ ) was overall higher than for the other two maturity stages. The mean emulsion stability of the pectin extracted from the ripe peels was much lower (34.5\%). This may be a consequence of the breakdown of protein [41] and the degradation of the neutral sugar side chain in the pectin molecules resulting from the activities of polygalacturonase and $\beta$-galactosidase [31] at this stage.

\subsection{Rheological Properties}

The results showed that the viscosity of mango peel pectin was strongly dependent on the temperature (Figure 2). The highest viscosity was obtained from running at $4{ }^{\circ} \mathrm{C}$, followed by $30^{\circ} \mathrm{C}$ and $50^{\circ} \mathrm{C}$. At all studied temperatures, Chu pectin showed the highest viscosity, which seems to be affected by the molecular weight (Table 1 ). 


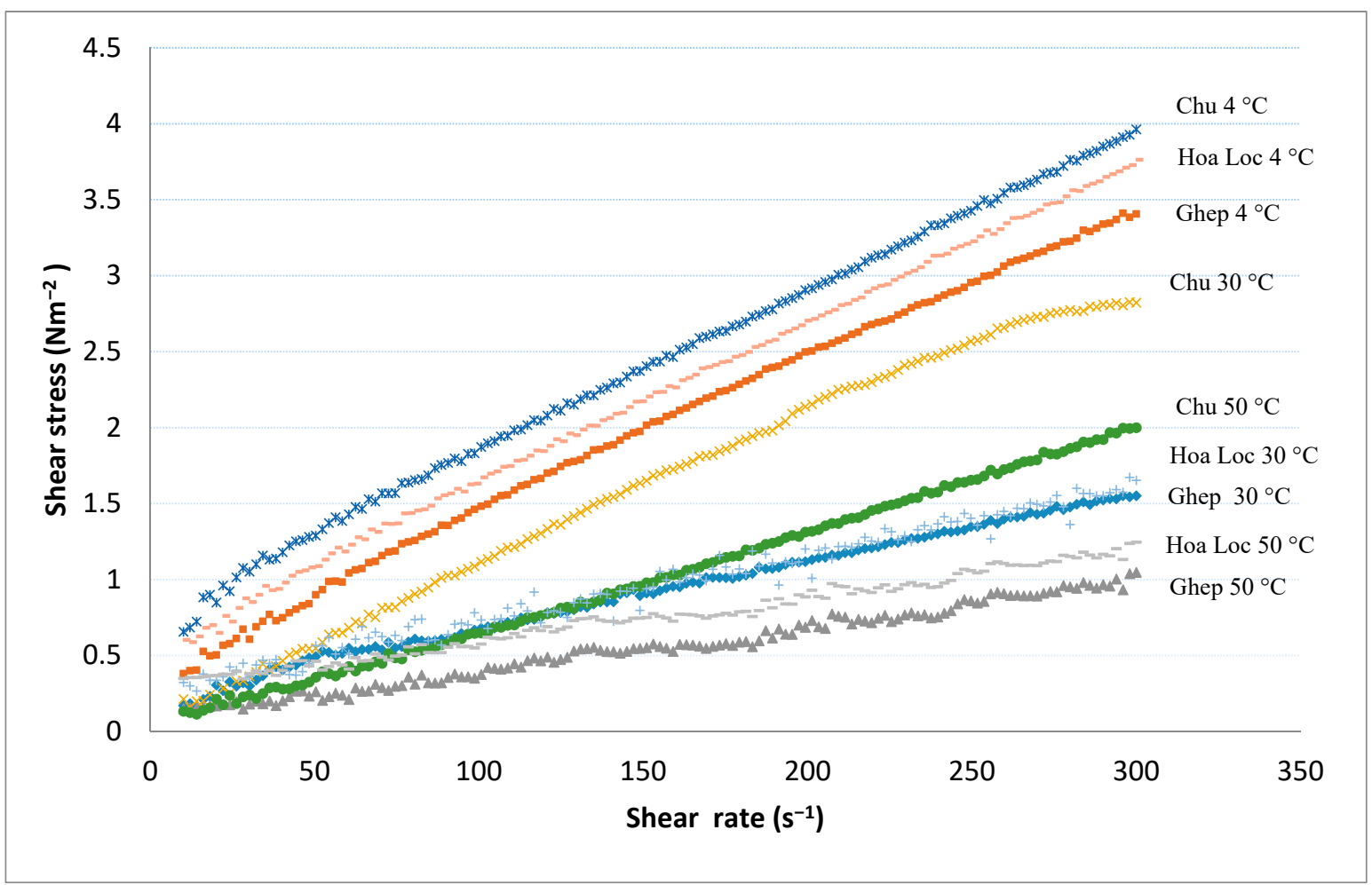

Figure 2. The effect of cultivars on viscosity of mango peel pectin solutions at different temperature.

\subsection{Viscosity-Average Molecular Weight}

In all studied varieties, the intrinsic viscosity and $\mathrm{M}_{\mathrm{W}}$ fluctuated depending on the maturation (Table 1). They increased from pre-mature to mature and then reduced as fruit ripened. The highest values were from Cat $\mathrm{Chu}$ pectin at the mature stage. The phenomenon was in agreement with those obtained in banana and kiwi fruit $[42,43]$. The changes of the intrinsic viscosity and $\mathrm{M}_{\mathrm{W}}$ could be due to pectinolytic enzymes including polygalacturonases and pectinmethylesterases [42]. As the $M_{w}$ ranged from 397.0 to $578.0 \mathrm{kDa}$, the pectin of the three mango cultivars can be considered as medium weight molecules. It is interesting to note that pectin extracted from Ghep and Hoa Loc peels had the higher values of degree of esterification; however, they had lower intrinsic viscosity and average molecular weight as correspondingly compared to those of Cat Chu. Similar observations for apple pomace and citrus peel pectin were recorded by Owens et al. [44] and Morris et al. [45].

\section{Conclusions}

This is the first study to investigate the properties of crude pectin extracted from Vietnamese mango peels discarded as waste. It can be inferred from this study that the mango peel pectin isolated at different maturities and cultivars has a significant range of different characteristics and therefore the potential to have an important role in food processing. In particular, the overall mean high esterification value of the extracted pectin suggests that it should be classified as high methoxyl pectin, which is of considerable interest to food processors.

Author Contributions: Methodology, H.H.D.N. and H.V.H.N.; writing—original draft preparation, H.H.D.N.; writing-review and editing, H.V.H.N. and G.P.S.; project administration, H.V.H.N.; funding acquisition, H.V.H.N.

Funding: This study was funded by Vietnam National University (the grant number C2014-28-04).

Acknowledgments: The authors wish to thank Huynh Ky Nha for her assistance in material preparation.

Conflicts of Interest: The authors declare no conflict of interest. 


\section{References}

1. Thakur, B.R.; Singh, R.K.; Handa, A.K. Chemistry and uses of pectin-A review. Crit. Rev. Food Sci. Nutr. 1997, 37, 47-73. [CrossRef] [PubMed]

2. Koubala, B.; Kansci, G.; Mbome, L.I.; Crepeau, M.-J.; Thibault, J.-F.; Ralet, M.-C. Effect of extraction conditions on some physicochemical characteristics of pectins from "Amelioree" and "Mango" mango peels. Food Hydrocoll. 2008, 22, 1345-1351. [CrossRef]

3. Elkner, K.; Kosson, R. Dietary fiber content and its fractional composition in cabbage as affected by cultivar earliness and sauerkraut storage period. Veg. Crops Res. Bull. 2008, 69, 165-175.

4. Sriamornsak, P. Chemistry of pectin and its pharmaceutical uses: A review. Silpakorn Univ. Int. J. 2003, 3, 206-228.

5. Al-Sheraji, S.H.; Ismail, A.; Manap, M.Y.; Mustafa, S.; Yusof, R.M.; Hassan, F.A. Functional properties and characterization of dietary fiber from Mangifera pajang Kort. fruit pulp. J. Agric. Food Chem. 2011, 59, 3980-3985. [CrossRef]

6. Nguyen, H.V.H.; Savage, G.P. The effects of temperature and $\mathrm{pH}$ on the extraction of oxalate and pectin from green kiwifruit (Actinidia deliciosa L.), golden kiwifruit (Actinidia chinensis L.), kiwiberry (Actinidia arguta) and persimmon (Diospyros kaki). Int. J. Food Sci. Tech 2013, 48, 794-800. [CrossRef]

7. Sogi, D.S.; Siddiq, M.; Greiby, I.; Dolan, K.D. Total phenolics, antioxidant activity, and functional properties of "Tommy Atkins" mango peel and kernel as affected by drying methods. Food Chem. 2013, 141, 2649-2655. [CrossRef]

8. El Bulk, R.E.; Babiker, E.F.E.; El Tinay, A.H. Changes in chemical composition of guava fruits during development and ripening. Food Chem. 1997, 59, 395-399. [CrossRef]

9. Zhou, H.C.; Li, G.; Zhao, X.; Li, L.J. Comparative analysis of polygalacturonase in the fruit of strawberry cultivars. Genet. Mol. Res. 2015, 14, 12776-12787. [CrossRef]

10. Belitz, H.D.; Grosch, W.; Schieberle, P. Fruits and Fruit Products. In Food Chemistry, 4th Revised and Extended edn; Belitz, H.-D., Grosch, W., Schieberle, P., Eds.; Springer: Berlin/Heidelberg, Germany, 2009; pp. 807-861.

11. Good Agricultural Practices (GAP) Library 2010. Available online: http://www.gap.org.vn (accessed on 28 October 2017).

12. Larrauri, J.A.; Ruperez, P.; Borroto, B.; Saura-Calixto, F. Mango peels as a new tropical fibre: Preparation and characterization. LWT Food Sci. Technol. 1996, 29, 729-733. [CrossRef]

13. Dorta, E.; Gloria, L.M.; Gonzalez, M. Using drying treatments to stabilize mango peel and seed: Effect on antioxidant activity. LWT Food Sci. Technol. 2012, 45, 261-268. [CrossRef]

14. Ajila, C.M.; Prasada Rao, U.J.S. Mango peel dietary fiber: Composition and associated bound phenolics. J. Funct. Foods 2013, 5, 444-450. [CrossRef]

15. The Observatory of Economic Complexity (OEC) Pectic Substances, Pectinates, Pectates. Available online: http://atlas.media.mit.edu/en/profile/hs92/130220/ (accessed on 20 December 2018).

16. Singthong, J.; Cui, S.W.; Ningsanond, S.; Goff, H.D. Structural characterization, degree of esterification and some gelling properties of Krueo Ma Noy (Cissamplelospareira) pectin. Carbohydr. Polym. 2004, 58, 391-400. [CrossRef]

17. Eastwood, M.A.; Robertson, J.A.; Brydon, W.G.; MacDonald, D. Measurement of water-Holding properties of fibre and their faecal bulking ability in man. Br. J. Nutr. 1983, 50, 539-547. [CrossRef] [PubMed]

18. Sciarini, L.S.; Maldonado, F.; Ribotta, P.D.; Perez, G.T.; Leon, A.E. Chemical composition and functional properties of Gleditsia triacanthos gum. Food Hydrocoll. 2009, 23, 306-313. [CrossRef]

19. Liang, Q.; Zhang, S.Q.; Zhang, J.S. Rheological behavior and microstructure of Oviductus Ranae hydrogels. Food Sci. Biotechnol. 2012, 21, 467-474. [CrossRef]

20. Kar, F.; Arslan, N. Effect of temperature and concentration on viscosity of orange peel pectin solutions and intrinsic viscosity-molecular weight relationship. Carbohydr. Polym. 1999, 40, 277-284. [CrossRef]

21. Kar, F.; Arslan, N. Characterization of orange peel pectin and effect of sugars, 1-ascorbic acid, ammonium persulfate, salts on viscosity of orange peel pectin solutions. Carbohydr. Polym. 1999, 40, 285-291. [CrossRef]

22. Owens, H.S.; Lotzkar, H.; Schultz, T.H.; Maclay, W.D. Shape and size of pectinic acid deduced from viscometric measurements. J. Am. Chem. Soc. 1946, 68, 1628-1632. [CrossRef]

23. Proctor, A.; Peng, L.C. Pectin transitions during blueberry fruit development and ripening. J. Food Sci. 1989, 54, 385-387. [CrossRef] 
24. Taylor, J.E. Exotics: Guava. In Biochemistry of Fruit Ripening; Seymour, G.B., Taylor, J.E., Tucker, G.A., Eds.; Springer: Dordrecht, The Netherlands, 1993; pp. 151-187.

25. Berardini, N.; Knodler, M.; Schieber, A.; Carle, R. Utilization of mango peels as a source of pectin and polyphenolics. Innov. Food Sci. Emerg. Technol. 2005, 6, 442-452. [CrossRef]

26. Gwynne, J. Chemistry in Its Element: Compounds. Royal Society of Chemistry. Available online: http://www. rsc.org/chemistryworld/podcast/CIIEcompounds/transcripts/pectin.asp(2015) (accessed on 30 December 2018).

27. Figuerola, F.; Hurtado, M.L.; Estevez, A.M.; Chiffelle, I.; Asenjo, F. Fibre concentrates from apple pomace and citrus peel as potential fibre sources for food enrichment. Food Chem. 2005, 91, 395-401. [CrossRef]

28. Yapo, B.M.; Koffi, K.L. Dietary fiber components in yellow passion fruit rind-A potential fiber source. J. Agric. Food Chem. 2008, 56, 5880-5883. [CrossRef] [PubMed]

29. Hasnaoui, N.; Wathelet, B.; Jimenez-Araujo, A. Valorization of pomegranate peel from 12 cultivars: Dietary fiber composition, antioxidant capacity and functional properties. Food Chem. 2014, 160, 196-203. [CrossRef] [PubMed]

30. Miyamoto, A.; Chang, K.C. Extraction and physicochemical characterization of pectin from sunflower head residues. J. Food Sci. 1992, 57, 1439-1443. [CrossRef]

31. Keller, M. Developmental Physiology. In The Science of Grapevines: Anatomy and Physiology; Keller, M., Ed.; Academic Press: Washington, DC, USA, 2015; pp. 196-268.

32. Kumar, A.; Chauhan, G.S. Extraction and characterization of pectin from apple pomace and its evaluation as lipase (steapsin) inhibitor. Carbohydr. Polym. 2010, 82, 454-459. [CrossRef]

33. Ismail, N.S.H.; Ramli, N.; Hani, N.M.; Meon, Z. Extraction and characterization of pectin from dragon fruit (Hylocereus polyrhizus) using various extraction conditions. Sains Malays. 2012, 41, 41-45.

34. Vriesmann, L.C.; Teofilo, R.F.; de Oliverira Petkowicz, C.L. Extraction and characterization of pectin from cacao pod husks (Theobroma cacao L.) with citric acid. LWT Food Sci. Technol. 2012, 49, 108-116. [CrossRef]

35. Anthon, G.E.; Barrett, D.M. Pectin methylesterase activity and other factors affecting $\mathrm{pH}$ and titratable acidity in processing tomatoes. Food Chem. 2012, 132, 915-920. [CrossRef]

36. Ng, J.K.T.; Schroder, R.; Sutherland, P.W.; Hallett, I.C.; Hall, M.I.; Prakash, R.; Smith, B.G.; Melton, L.D.; Johnston, J. Cell wall structures leading to cultivar differences in softening rates develop early during apple (Malus x domestica) fruit growth. BMC Plant Biol. 2013, 13, 1-16. [CrossRef]

37. Gnanasambandam, R.; Proctor, A. Determination of pectin degree of esterification by diffuse reflectance Fourier transform infrared spectroscopy. Food Chem. 2000, 68, 327-332. [CrossRef]

38. Lopez-Franco, Y.L.; Gooycolea, F.M.; Lizardi-Mendoza, J. Gum of Prosopis/Acacia Species. In Polysaccharides: Bioactivity and Biotechnology; Kishan Gopal, K., Jean-Michel Mérillon, R., Eds.; Springer International Publishing: Berlin/Heidelberg, Germany, 2015; pp. 1-20.

39. Ngouémazong, E.D.; Christiaens, S.; Shpigelman, A.; Loey, A.V.; Hendrickx, M. The emulsifying and emulsion-Stabilizing properties of pectin: A review. Compr. Rev. Food Sci. Food Saf. 2015, 14, 705-718. [CrossRef]

40. Fasoli, E.; Righetti, P.G. The peel and pulp of mango fruit: A proteomic samba. Biochim Biophys Acta Proteins Proteom. 2013, 1834, 2539-2545. [CrossRef] [PubMed]

41. Abu-Goukh, A.A.; Shattir, A.E.T.; Mahdi, E.F.M. Physico-chemical changes during growth and development of papaya fruit. II: Chemical changes. Agric. Biol. J. N. Am. 2010, 1, 871-877. [CrossRef]

42. Emaga, T.H.; Robert, C.; Ronkart, S.N.; Wathelet, B.; Paquot, M. Dietary fiber components and pectin chemical features of peels during ripening in banana and plaintain varieties. Bioresour. Technol. 2008, 99, 4346-43454. [CrossRef] [PubMed]

43. Yuliarti, O.; Matia-Merino, L.; Goh, K.K.T.; Mawson, J.; Williams, M.A.K.; Brennan, C. Characterization of gold kiwifruit pectin from fruit of different maturities and extraction methods. Food Chem. 2015, 166, 479-485. [CrossRef] 
44. Owens, H.S.; McCready, R.M.; Shepherd, A.D.; Schultz, S.H.; Pippen, E.L.; Swenson, H.A.; Miers, J.C.; Erlandsen, R.F.; Maclay, W.D. Methods Used at Western Regional Research Laboratory for Extraction and Analysis of Pectic Materials; Western Regional Research Laboratory: Albany, CA, USA, 1952; AIC-340.

45. Morris, G.A.; Foster, T.J.; Harding, S.E. The effect of the degree of esterification on the hydrodynamic properties of citrus pectin. Food Hydrocoll. 2000, 14, 227-235. [CrossRef]

(C) 2019 by the authors. Licensee MDPI, Basel, Switzerland. This article is an open access article distributed under the terms and conditions of the Creative Commons Attribution (CC BY) license (http://creativecommons.org/licenses/by/4.0/). 